\title{
Prevalence and correlates of probable depression diagnosis and suicidal ideation among patients receiving HIV care in Lilongwe, Malawi
}

\section{Jullita K. Malava ${ }^{1,2}$, Kathryn E. Lancaster ${ }^{3}$, Mina C. Hosseinipour ${ }^{1,3}$, Nora E. Rosenberg ${ }^{1,4}$, Julie K. O'Donnell ${ }^{4}$, Felix Kauye ${ }^{2,5}$, Noel Mbirimtengerenji ${ }^{6}$, Thom Chaweza ${ }^{7}$, Hannock Tweya ${ }^{7}$, Sam Phiri ${ }^{2,3,7}$, Brian W. Pence ${ }^{4}$, Bradley N. Gaynes $^{8}$}

1. UNC Project Malawi, University of North Carolina at Chapel Hill, Lilongwe, Malawi

2. College of Medicine, University of Malawi, Blantyre, Malawi

3. Division of Infectious Diseases, School of Medicine, University of North Carolina at Chapel Hill, 130 Mason

Farm Rd, Chapel Hill, North Carolina, 27599, United States of America

4. Department of Epidemiology, Gillings School of Global Public Health, The University of North Carolina at

Chapel Hill, 135 Dauer Drive, Chapel Hill, North Carolina, 27599, United States of America

5. Zomba Mental Hospital, Zomba, Malawi

6. Kamuzu College of Nursing, University of Malawi, Lilongwe, Malawi

7. Lighthouse Medical Trust, Lilongwe, Malawi

8. Department of Psychiatry, School of Medicine, University of North Carolina at Chapel Hill, 101 Manning

Drive, Chapel Hill, North Carolina, 27599, United States of America
Date Received: 12-Feb-2017

Revisions Received: 13-Dec-2017

Date Accepted: 24-Jan-2018

Correspondence: Kathryn E.

Lancaster (kathryn_lancaster@

med.unc.edu)

\section{Abstract}

\section{Background}

Depression and suicide ideation among people living with HIV (PLHIV) can threaten the success of HIV care and treatment programs, particularly within high HIV prevalence settings. We describe the prevalence and correlates associated with depression and suicidal ideation among PLHIV receiving HIV care in Lilongwe, Malawi.

Methods

From July to September 2013, 206 HIV clinic patients, who were $\geq 18$ years of age and either pre-antiretroviral therapy (ART) or established on ART for $\geq 6$ months prior to study, participated in a survey to assess the prevalence of a likely depressive disorder and suicidal ideation using the Patient Health Questionnaire-9. We explored factors associated with depression using bivariable linear regression and suicidal ideation using bivariable log-binomial regression.

\section{Results}

The prevalence of a likely depressive disorder and suicidal ideation was 12\% (95\% CI: 8\%, 17\%) and 16\% (95\% CI: 11\%, 21\%), respectively. Pre-ART patients $(\beta=1.17,95 \%$ CI: 0.03, 2.30, p-value $=0.04)$ and those with problematic alcohol use $(\beta=0.49,95 \%$ CI: 0.07, 0.92 , $\mathrm{p}$-value $=0.02)$ were associated with a higher depression severity. Suicidal ideation was relatively common $(8 \%, 95 \% \mathrm{CI}$ : $5 \%, 13 \%$ among those without a likely depressive disorder and significantly correlated with having no primary, secondary, or tertiary education ( $\beta=-1.52$, 95\% CI: $-2.46,-0.59$, p-value $<0.01)$.

Conclusions

Interventions that enhance identification and management of depressive disorders and suicidal ideation should be integrated within HIV care clinics in Malawi.

Key words: epidemiology, public health, infectious diseases

\section{Introduction}

People living with HIV (PLHIV) are disproportionately affected by depression. Within high HIV prevalence settings, such as sub-Saharan Africa, the prevalence of depression symptoms ranges from $18 \%$ to $80 \%$ among PLHIV, which is notably higher than the depression symptoms prevalence among the general population ${ }^{1}$. Depression among PLHIV is strongly and consistently associated with reduced antiretroviral therapy (ART) adherence ${ }^{1,2}$. Depression can also lead to high-risk sexual behaviors that ultimately may increase the likelihood of HIV transmission to uninfected partners ${ }^{3-5}$. To improve treatment outcomes and prevent ongoing transmission, depression must be diagnosed among PLHIV for optimal engagement in HIV care and treatment. The intrinsic relationship between depression and HIV is complex with adverse effects on HIV care and treatment engagement. Depression can precede HIV acquisition or can be a consequence of HIV infection. After an HIV diagnosis, underlying depression can worsen or be induced by infection awareness ${ }^{2,7}$. In many settings globally, PLHIV who have depression have suboptimal engagement and retention in care and poor antiretroviral adherence, which as a result, leads to poor clinical outcomes ${ }^{8-14}$.

Although it is well-established that depression leads to poor HIV outcomes, depression is often undetected and untreated among PLHIV. Particularly within sub-Saharan Africa, limited skilled mental health professionals are overburdened and mental health services for PLHIV are scarce ${ }^{7,15,16}$. In Malawi, where the HIV prevalence is approximately $9 \%$ among women and men aged 15-49 years, there is a severe lack of trained mental health care professionals and a knowledge gap of current prevalence and correlates 
of depression among PLHIV accessing treatment ${ }^{17,18}$ Those with depression are also at greater risk for suicidal ideation ${ }^{19,20}$. However, few have examined suicidal ideation among PLHIV in high HIV prevalent settings, such as subSaharan Africa ${ }^{21,22}$. Without a proper understanding of the relationships between depression, including suicidal ideation, ART, and other factors in sub-Saharan African settings, it will be difficult to know how best to direct scarce resources.

Given the limited literature on depression and especially, suicidal ideation among PLHIV, the primary purpose for this formative study was to inform future, prospective, appropriately-powered studies on depression and suicidal ideation among PLHIV in Malawi. We assessed the prevalence of depression and suicidal ideation and explored factors associated with depression and suicidal ideation among people living with HIV, including pre-ART and established ART patients, receiving HIV care in Lilongwe, Malawi.

\section{Methods}

\section{Study design and population}

We conducted a descriptive, cross-sectional study from July to September 2013 in Lighthouse Trust, an HIV prevention, treatment and care clinic located in Lilongwe, Malawi. The Lighthouse Trust clinic provides HIV testing and counseling, HIV primary care, management of opportunistic infections, ART care, cervical cancer screening, and family planning for all people living with HIV, in addition to conducting operations research. To systematically identify participants, we selected every third patient visiting the Lighthouse Trust clinic to assess eligibility for participation. Inclusion criteria were at least 18 years of age, men and women living with HIV who registered and receiving care from Lighthouse Trust clinic, either pre-ART or on established ART for at least 6 months prior to study participation, and willing and able to provide informed consent. Exclusion criteria were less than 18 years of age, reported use of psychiatric drugs, on ART for less than 6 months prior to study participation, or possessing cognitive impairment or physical limitations that would prevent participation.

Participants found to be depressed with a score of 10 or higher on the Patient Health Questionnaire-9 (PHQ-9) ${ }^{23}$ were referred to Bwaila Mental Hospital for additional care and those experiencing acute suicidal ideation were referred for immediate assistance and care.

\section{Data collection}

Participants who provided informed consent received an interviewer-administered structured questionnaire to collect detailed information on demographics, HIV care, ART history, social and sexual behavior, alcohol use, suicidal ideation, and depression. The questionnaire was translated and back-translated from English to Chichewa, the predominant language in Malawi. Both English and Chichewa versions of the questionnaire were available to participants. To determine the prevalence of depression, we used the PHQ-9 to assess the presence of the 9 core symptoms of depression within the past two weeks as specified by the DMS-IV ${ }^{23}$. The PHQ9 has been internationally validated in several clinics within resource limited settings ${ }^{24-26}$. Scores range between 0 and 27 , with a score of 10 or higher indicative of the presence of a likely clinically significant depressive disorder. Scores are also grouped by severity into the following categories: $<5$ no depression, 5-9 as mild depression (although not considered a depressive illness that would require treatment), 10-19 as moderate depression, and 20-27 as severe depression. The PHQ-9 was developed to be self-administered, however, interview administration has yielded similar results ${ }^{27}$, and thus was used in this way in this study.

Suicidal ideation was assessed using question 9 on the PHQ9, which states "During the past two weeks how often have you had thoughts that you would be better off dead or hurting yourself in some way?" Responses included: "not at all, several days, more than half the days, or nearly every day". Any response other than "not at all" was considered experiencing suicidal ideation.

Potential factors associated with depression were identified through a review of the literature and included: sexual behaviours, such as more sexual partners in the last month, more sexual encounters in the last month by primary and casual partnership, higher number and proportion of condom use in the last month by primary and casual partnership, increased alcohol use, measured using the Cutting down, Annoyance by criticism, Guilty feelings, and Eye-openers (CAGE) assessment $(0=$ no risk; $1=$ at risk; $2=$ current problem; $3=$ dependence), comorbidities with HIV (yes vs. no), HIV disclosure to at least one person (yes vs. no), and self-reported ART adherence (number of pills missed) ${ }^{1,2,6,28,29}$. A parsimonious set of potential factors associated with suicidal ideation included: ART use (preART vs established ART), marital status (married vs. not married), HIV disclosure to at least one person (yes vs. no), and education (no education vs. any primary, secondary, or tertiary $)^{30-33}$.

\section{Statistical analysis}

We describe patient characteristics and sexual behaviors by ART use with frequencies and proportions for categorical variables and means and standard deviations (SD) for continuous variables. We examined the prevalence of depression and suicidal ideation for the total population and compared those pre-ART vs. established ART using Pearson's Chi-squared tests for categorical variables. We used bivariable linear regression to explore factors associated with depression and bivariable log-binomial regression to explore an a priori set factors associated with suicidal ideation. A p-value less than 0.05 was considered statistically significant statistical trends were noted. Data were analyzed using STATA version 12.0 software package.

\section{Results}

\section{Study cohort characteristics}

Of the 223 patients sampled, 206 (92\%) were eligible and provided informed consent. Six patients (3\%) were ineligible for participation and $11(5 \%)$ declined participation in the study. Of the 206 paticipants who consented, $103(50 \%)$ were pre-ART and $103(50 \%)$ were established on ART. Of the 206 participants receiving HIV care, the mean age for this study population was 38 years $(\mathrm{SD}=10)$ and $59 \%(\mathrm{n}=121)$ were female (Table 1). Approximately $60 \%(n=129)$ were married and living with their partner. Most had received primary education $(46 \% ; \mathrm{n}=46)$ and were living in unburned brick housing structures (56\%). About one-third had running water $(36 \% ; n=74)$ or electricity in their home $(32 \% ; n=66)$. Nearly all had disclosed their HIV status $(94 \% ; n=193)$ to at least one person. The mean number of sexual partners in the past month was 1.21 (SD: 6.18). Using the CAGE assessment, $11 \%(\mathrm{n}=23)$ were considered to have at-risk drinking (CAGE score $=1), 18 \%(\mathrm{n}=37)$ were considered to 
have current problem drinking (CAGE score=2), and 19\% $(n=40)$ were considered to have dependent drinking (CAGE score $\geq 3$ ).

Table 1: Patient characteristics and sexual behaviors by ART use among people living with HIV receiving HIV care in Lilongwe, Malawi, July to September 2013; N=206

\begin{tabular}{|c|c|c|c|}
\hline & $\begin{array}{l}\text { Total } \\
\mathrm{N}=206\end{array}$ & $\begin{array}{l}\text { Pre-ART } \\
N=103\end{array}$ & $\begin{array}{l}\text { Established } \\
\text { ART } \\
N=103\end{array}$ \\
\hline & \multicolumn{3}{|c|}{ Mean (SD) or $n(\%)$} \\
\hline Age, mean & $38(10)$ & $36(9)$ & $39(11)$ \\
\hline \multicolumn{4}{|l|}{ Gender } \\
\hline Male & $84(41 \%)$ & $47(46 \%)$ & $37(36 \%)$ \\
\hline Female & $121(59 \%)$ & $55(53 \%)$ & $66(64 \%)$ \\
\hline \multicolumn{4}{|l|}{ Marital status } \\
\hline $\begin{array}{l}\text { Married living } \\
\text { with partner }\end{array}$ & $129(63 \%)$ & $57(55 \%)$ & $72(70 \%)$ \\
\hline $\begin{array}{l}\text { Married living } \\
\text { apart from partner }\end{array}$ & $15(7 \%)$ & $10(10 \%)$ & $5(5 \%)$ \\
\hline Widowed & $25(12 \%)$ & $12(12 \%)$ & $13(13 \%)$ \\
\hline $\begin{array}{l}\text { Divorced/ } \\
\text { separated }\end{array}$ & $28(14 \%)$ & $20(19 \%)$ & $8(8 \%)$ \\
\hline Never married & $9(4 \%)$ & $4(4 \%)$ & $5(5 \%)$ \\
\hline \multicolumn{4}{|l|}{ Education } \\
\hline None & $30(15 \%)$ & $13(13 \%)$ & $17(17 \%)$ \\
\hline Primary & $94(46 \%)$ & $47(46 \%)$ & $47(46 \%)$ \\
\hline Secondary & $64(31 \%)$ & $34(33 \%)$ & $30(29 \%)$ \\
\hline Tertiary & $18(9 \%)$ & $9(9 \%)$ & $9(9 \%)$ \\
\hline \multicolumn{4}{|l|}{ Housing type } \\
\hline Poles and grass & 0 & 0 & 0 \\
\hline Unburned bricks & $115(56 \%)$ & $60(58 \%)$ & $55(53 \%)$ \\
\hline $\begin{array}{l}\text { Burnt bricks and } \\
\text { mud }\end{array}$ & $30(15 \%)$ & $15(15 \%)$ & $15(15 \%)$ \\
\hline $\begin{array}{l}\text { Burnt bricks and } \\
\text { cement }\end{array}$ & $61(30 \%)$ & $28(27 \%)$ & $33(32 \%)$ \\
\hline \multicolumn{4}{|l|}{ Water in home } \\
\hline Yes & $74(36 \%)$ & $38(37 \%)$ & $36(35 \%)$ \\
\hline No & $132(64 \%)$ & $65(63 \%)$ & $67(65 \%)$ \\
\hline \multicolumn{4}{|l|}{ Electricity in home } \\
\hline Yes & $66(32 \%)$ & $35(34 \%)$ & $31(30 \%)$ \\
\hline No & $140(68 \%)$ & $68(66 \%)$ & $72(70 \%)$ \\
\hline \multicolumn{4}{|l|}{$\begin{array}{l}\text { HIV status } \\
\text { disclosure }\end{array}$} \\
\hline Yes & $193(94 \%)$ & $90(87 \%)$ & $103(100 \%)$ \\
\hline No & $13(6 \%)$ & $13(13 \%)$ & 0 \\
\hline \multicolumn{4}{|l|}{ ART adherence } \\
\hline $\begin{array}{l}\text { Mean number } \\
\text { of pills missed, } \\
\text { past month }\end{array}$ & - & - & $0.73(1.72)$ \\
\hline \multicolumn{4}{|l|}{$\begin{array}{l}\text { On long-term } \\
\text { treatment } \\
\text { other than ART }\end{array}$} \\
\hline Yes & $27(13 \%)$ & $13(13 \%)$ & $14(14 \%)$ \\
\hline No & $179(87 \%)$ & $90(87 \%)$ & $89(86 \%)$ \\
\hline
\end{tabular}

Living with an

illness

other than

HIV

Yes $\quad 37(18 \%) \quad 19(18 \%) \quad 18(17 \%)$

No $\quad 169(82 \%) \quad 84(82 \%) \quad 85(83 \%)$

Mean number of

sexual partners,

past

$1.21(6.18) \quad 1.7(8.7)$

$0.70(0.50)$

month

Mean number of

sexual

encounters,

past month

\begin{tabular}{|c|c|c|c|}
\hline Primary partner & $5.66(6.53)$ & $6.41(7.36)$ & $4.92(5.54)$ \\
\hline Casual partner & $16.64(30.84)$ & $20.64(33.97)$ & $2.00(1.73)$ \\
\hline \multicolumn{4}{|l|}{$\begin{array}{l}\text { Mean number of } \\
\text { times using a } \\
\text { condom, past } \\
\text { month }\end{array}$} \\
\hline Primary partner & $4.25(5.59)$ & $4.52(6.53)$ & $3.98(4.51)$ \\
\hline Casual partner & $11.09(25.62)$ & $12.89(28.30)$ & $3.00(0)$ \\
\hline \multicolumn{4}{|l|}{$\begin{array}{l}\text { Proportion of } \\
\text { encounters } \\
\text { protected, } \\
\text { past month }\end{array}$} \\
\hline Primary partner & $0.72(0.37)$ & $0.64(0.41)$ & $0.79(0.32)$ \\
\hline Casual partner & $0.84(0.34)$ & $0.80(0.37)$ & $1.00(0.00)$ \\
\hline \multicolumn{4}{|l|}{ Alcohol use } \\
\hline $\begin{array}{l}\text { No risk, CAGE } \\
\text { score }=0\end{array}$ & $106(51 \%)$ & $36(35 \%)$ & $70(68 \%)$ \\
\hline $\begin{array}{l}\text { At risk, CAGE } \\
\text { score }=1\end{array}$ & $23(11 \%)$ & $17(17 \%)$ & $6(6 \%)$ \\
\hline $\begin{array}{l}\text { Current problem, } \\
\text { CAGE score }=2\end{array}$ & $37(18 \%)$ & $27(26 \%)$ & $10(10 \%)$ \\
\hline $\begin{array}{l}\text { Dependence, } \\
\text { CAGE score } \geq 3\end{array}$ & $40(19 \%)$ & $23(22 \%)$ & $17(17 \%)$ \\
\hline
\end{tabular}

SD: Standard deviation; CAGE: Cutting down, Annoyance by criticism, Guilty feelings, and Eye-openers assessment

\section{Prevalence and correlates of depression}

The mean PHQ-9 score was $4(\mathrm{SD}=4)$. Overall, the prevalence of a likely depressive disorder (PHQ-9 score $\geq 10$ ) was 12\% (95\% CI: $8 \%, 17 \%$ ) (Table 2). $23 \%$ of all the participants had mild depression not severe enough to indicate the presence of a depressive disorder (PHQ-9 score 5-9) or require specific treatment. 12\% had moderate depression (PHQ score 10-19) and no participants reported severe depression (PHQ-9 score $\geq 20$ ). The prevalence of depression was comparable across both those pre-ART and established on ART (16\% vs. 9\%, p value $=0.24)$. Pre-ART patients had 1.17-point higher PHQ9 score (95\% CI: 0.03, 2.30, p value $=0.04)$ when compared to established ART patients (Table 3). Not being married $(\beta=0.32,95 \%$ CI: $-0.92,1.57, \mathrm{p}$ value $=0.61)$ and having no primary, secondary, or tertiary education $(\beta=-1.03,95 \% \mathrm{CI}$ : $-2.64,0.58, \mathrm{p}$ value $=0.21)$ were not significantly correlated with depression. 
Table 2: Prevalence of depression and suicidal ideation by ART use among people living with HIV receiving HIV care in Lilongwe, Malawi (July to September 2013); N=206

\begin{tabular}{|c|c|c|c|c|}
\hline & $\begin{array}{l}\text { Total } \\
\mathrm{N}=206\end{array}$ & $\begin{array}{l}\text { Pre-ART } \\
\mathrm{N}=103\end{array}$ & $\begin{array}{l}\text { Established } \\
\text { ART } \\
N=103\end{array}$ & $p$-value \\
\hline & & $\mathrm{n}(\%)$ & & \\
\hline $\begin{array}{l}\text { Depression, } \\
\text { PHQ-9 }\end{array}$ & & & & 0.24 \\
\hline $\begin{array}{l}\text { No depression, } \\
\text { score }<5\end{array}$ & $134(65 \%)$ & $62(60 \%)$ & $72(70 \%)$ & \\
\hline $\begin{array}{l}\text { Mild depression, } \\
\text { score 5-9 }\end{array}$ & $47(23 \%)$ & $25(24 \%)$ & $22(21 \%)$ & \\
\hline $\begin{array}{l}\text { Moderate } \\
\text { depression, } \\
\text { score } \\
10-19\end{array}$ & $25(12 \%)$ & $16(16 \%)$ & $9(9 \%)$ & \\
\hline $\begin{array}{l}\text { Severe } \\
\text { depression, } \\
\text { score } \\
20-27\end{array}$ & 0 & 0 & 0 & \\
\hline $\begin{array}{l}\text { Suicidal } \\
\text { ideation }\end{array}$ & & & & 0.05 \\
\hline Yes & $32(16 \%)$ & $21(20 \%)$ & $11(11 \%)$ & \\
\hline No & $174(84 \%)$ & $82(80 \%)$ & $92(89 \%)$ & \\
\hline
\end{tabular}

PHQ-9: Patient Health Questionnaire

Table 3: Bivariable results for factors associated with depression severity (continuous PHQ-9 score) among people living with HIV receiving HIV care in Lilongwe, Malawi (July to September 2013); $\mathrm{N}=206$

\begin{tabular}{|c|c|c|c|}
\hline & Coefficient & $95 \% \mathrm{Cl}$ & $\mathrm{p}$-value \\
\hline \multicolumn{4}{|l|}{ Marital status } \\
\hline Not married & 0.32 & $(0.92,1.57)$ & 0.61 \\
\hline Married & reference & & \\
\hline \multicolumn{4}{|l|}{ Education } \\
\hline $\begin{array}{l}\text { No primary, } \\
\text { secondary, or tertiary }\end{array}$ & -1.03 & $(-2.64,0.58)$ & 0.21 \\
\hline $\begin{array}{l}\text { Any primary, } \\
\text { secondary, or tertiary }\end{array}$ & reference & & \\
\hline \multicolumn{4}{|l|}{ ART use } \\
\hline Pre-ART & 1.17 & $(0.03,2.30)$ & 0.04 \\
\hline Established ART & reference & & \\
\hline \multicolumn{4}{|l|}{ HIV status disclosure } \\
\hline Yes & reference & & \\
\hline No & -0.19 & $(-2.54,2.15)$ & 0.87 \\
\hline \multicolumn{4}{|l|}{ ART adherence } \\
\hline $\begin{array}{l}\text { Number of pills } \\
\text { missed, past month }\end{array}$ & -0.12 & $(-0.57,0.32)$ & 0.59 \\
\hline \multicolumn{4}{|l|}{$\begin{array}{l}\text { On long-term } \\
\text { treatment other } \\
\text { than ART }\end{array}$} \\
\hline Yes & 0.71 & $(-0.98,2.40)$ & 0.40 \\
\hline No & reference & & \\
\hline \multicolumn{4}{|l|}{$\begin{array}{l}\text { Living with an } \\
\text { illness other than HIV }\end{array}$} \\
\hline Yes & 0.42 & $(-1.06,1.91)$ & 0.58 \\
\hline
\end{tabular}

No

Number of sexual partners, past month

$-0.04$

Number of sexual

encounters,

past month

Primary partner

Casual partner

Number of times using a condom, past month

Primary partner

Casual partner

Proportion of

encounters

protected, past month

\section{Primary partner}

$-0.65$

Casual partner

$-0.99$

Alcohol use

CAGE score,

continuous

0.49

$\begin{array}{lll}-0.07 & (-0.17,0.03) & 0.15 \\ -0.01 & (-0.11,0.09) & 0.80\end{array}$

$-0.10$

$(-0.22,0.02) \quad 0.11$

$-0.09$

$(-0.21,0.03) \quad 0.14$

More problematic alcohol use, as indicated by a higher CAGE score, was significantly correlated with depression, with a $\mathrm{p}$ value $=0.02$. Every one point increase on the CAGE was associated with a 0.49 -point $(95 \% \mathrm{CI}: 0.07,0.92)$ higher PHQ-9 score. The number of times using a condom with both primary partners $(\beta=-0.10,95 \%$ CI: $-0.22,0.02, p$ value $=0.11)$ and casual partners $(\beta=-0.21,95 \%$ CI: -0.21 , 0.03 , $\mathrm{p}$ value $=0.14)$ was associated with lower depression scores, although not statically significant. There was little to no correlation between number of missed pills and PHQ9 score for depression $(\beta=-0.12,95 \%$ CI: $-0.57,0.32, p$ value $=0.59)$.

Table 4: Prevalence of suicidal ideation by depression among people living with HIV receiving HIV care in Lilongwe, Malawi, July to September 2013; N=206

\begin{tabular}{lllll}
\hline & $\begin{array}{l}\text { Total } \\
\mathrm{N}=206\end{array}$ & $\begin{array}{l}\mathrm{PHQ}-9 \text { score } \\
\geq 10 \\
\mathrm{~N}=25\end{array}$ & $\begin{array}{l}\mathrm{PHQ}-9 \text { score } \\
<10 \\
\mathrm{~N}=181\end{array}$ & p-value \\
\hline & & $\mathrm{n}(\%)$ & $<0.01$ \\
$\begin{array}{l}\text { Suicidal } \\
\text { ideation }\end{array}$ & & & \\
Yes & $32(16 \%)$ & $17(68 \%)$ & $15(8 \%)$ & \\
No & $174(84 \%)$ & $8(32 \%)$ & $166(92 \%)$ & \\
\hline
\end{tabular}

\section{Prevalence and correlates of suicidal ideation}

The prevalence of suicidal ideation among all the participants, independent of depression status, was 16\% (95\% CI: $11 \%$, $21 \%$ ) (Table 2). When compared to those established on ART, pre-ART participants were more likely to have suicidal ideation $(20 \%$ versus $11 \%$; p value $=0.05)$. The suicidal ideation prevalence among those with a likely depressive disorder was 68\%, $\mathrm{n}=17$ (Table 4). Among those without a likely depressive disorder, the prevalence of suicidal ideation was 8\% (95\% CI: 5\%, 13\%), $n=15$. In bivariable log binomial regression (Table 5), marital status $(\beta=-0.53$, $95 \%$ CI: $-1.76,0.69$, p value $=0.40)$, ART use $(\beta=0.48,95 \%$ CI: $-0.51,1.47$, p value $=0.43)$ and HIV disclosure $(\beta=0.87$, $95 \%$ CI: $-0.49,2.22$, p value $=0.21)$ were not associated with 
suicidal ideation among those without a likely depressive disorder. While, having no primary, secondary, or tertiary education $(\beta=-1.52,95 \% \mathrm{CI}:-2.46,-0.59$, $\mathrm{p}$ value $<0.01)$ was significantly associated with suicidal ideation among those without a likely depressive disorder.

Table 5: A prior set of factors associated with suicidality among people without depression (PHQ-9 score $<10$ ) and living with HIV receiving HIV care in Lilongwe, Malawi (July to September 2013); $\mathrm{N}=181$

\begin{tabular}{llll}
\hline & \multicolumn{1}{c}{ Coefficient } & $95 \% \mathrm{Cl}$ & $\mathrm{p}$-value \\
\hline $\begin{array}{l}\text { Marital status } \\
\text { Not married }\end{array}$ & $\begin{array}{l}-0.53 \\
\text { reference }\end{array}$ & $(-1.76,0.69)$ & 0.40 \\
$\begin{array}{l}\text { Earried } \\
\text { Education }\end{array}$ & & & \\
$\begin{array}{l}\text { No primary, } \\
\text { secondary, or } \\
\text { tertiary }\end{array}$ & -1.52 & $(-2.46,-0.59)$ & 0.01 \\
$\begin{array}{l}\text { Any primary, } \\
\text { secondary, } \\
\text { tertiary }\end{array}$ & & & \\
ART use & reference & & \\
$\quad$ Pre-ART & 0.48 & $(-0.51,1.47)$ & 0.43 \\
$\quad$ Established ART & reference & & \\
HIV status & & & \\
disclosure & & & \\
Yes & reference & & \\
No & 0.87 & $(-0.49,2.22)$ & 0.21 \\
\hline
\end{tabular}

\section{Discussion}

This study was one of the first to assess the prevalence of depression and suicidal ideation using a brief depression screening tool within an HIV clinic population in Malawi. In this sample of HIV clinic patients either pre-ART or on established ART in Malawi, approximately one in ten had a likely depressive disorder, according to the PHQ-9. Suicidal ideation prevalence was nearly $20 \%$ with a noticeable proportion of patients with suicidal ideation that were likely not depressed according to the PHQ-9. Problematic alcohol use was statistically significantly associated with greater depression severity. ART adherence, ascertained through self-reported pill count, was not associated with depression score.

The likely depressive disorder prevalence within our sample of PLHIV is comparable with prevalence estimates from other settings in sub-Saharan Africa ${ }^{1}$. The pooled prevalence of major depression diagnosed by diagnostic interviews was $18 \%{ }^{1}$. Among PLHIV in rural HIV clinics of Mzuzu, Malawi, the prevalence of psychological distress, including depression, determined using the Self Reporting Questionnaire (SRQ) was 14\% $0^{34}$. The variation between our depression prevalence and others is likely due to the variety of diagnostic interviews or depression screening tools used, some of which have not been validated. The PHQ-9, which was used within this study, has not specifically been validated within Malawi, however, it has good sensitivity and specificity for depression among PLHIV in other SSA settings, supporting the use within this context $\mathrm{t}^{24,25}$. Also, it is important to note that the interviewer assisted screening of depression may lead to the underreporting of depressive symptoms. The high prevalence of likely depressive disorder emphasizes the importance of depression screening among PLHIV receiving HIV care. Surprisingly, the prevalence of suicidal ideation was higher than the overall depression prevalence within this sample, which was contrary to previous findings in Malawi. This result was unexpected given individuals with active suicidal thoughts generally also have a likely depressive disorder ${ }^{20}$. Suicidal ideation has also been previously associated with recent diagnosis ${ }^{30}$. Within our sample, suicidal ideation was not correlated with pre-ART patients, who likely had a recent HIV diagnosis. Improvements in access to ART and health outcomes among PLHIV in Malawi may explain this lack of association ${ }^{35,36}$. Nonetheless, a deeper understanding is strongly needed of the underlying pathways for the presence of suicidal ideation among those without likely depressive disorder.

Depression has consistently been linked with higher rates of heavy drinking and alcohol use disorders among PLHIV ${ }^{37,38}$. Within our sample, more problematic alcohol use was strongly associated with likely depressive disorder. Due to the cross-sectional nature of this study, we were unable to determine the temporal order of alcohol use and depression. Nonetheless, the risk factors for problematic alcohol use can be driven by depressive symptoms and when undiagnosed and untreated, depression likely leads to increased alcohol use over time $\mathrm{e}^{39-41}$. The co-occurring conditions of depression and problematic alcohol use among PLHIV is particularly concerning given the adverse effects on health and treatment outcomes, such as poor ART adherence and greater HIV disease progression ${ }^{1,7}$. Alcohol reduction interventions including brief interventions, social skills training, and reinforcement approach are effective and should be explored among PLHIV within resource limited settings ${ }^{42}$. Likely depressive disorders should be identified and treated to also potentially reduce problematic alcohol use.

Among our sample, ART adherence was not associated with likely depressive disorder. It has been widely documented that depression leads to poor ART adherence ${ }^{1,2,43}$. Our lack of association may be explained by our self-reported measurement of ART adherence, which relies on the veracity of the patients' reports. Future studies should incorporate validated ART adherence measurements to enhance the understanding of ART adherence and depression among PLHIV in Malawi. Furthermore, our sample was among a small sample of those receiving care at an HIV clinic within Lilongwe. A larger sample among those receiving HIV care and not receiving HIV care would not only be more representative of PLHIV in Malawi, but would also capture those with depression that are not engaged in HIV care and therefore, not ART adherent. The cross-sectional nature of our study does not allow for the assessment of temporality of the factors associated with depression and suicidal ideation. Although our study had relatively small sample size, we were able to explore the prevalence and correlates with depression and suicidal ideation using bivariable analyses. Future prospective, appropriately powered studies will enhance our findings.

\section{Conclusions}

Overall, our study presents important data on factors that could predict depression and suicidal ideation among PLHIV in Malawi. These findings highlight the need to screen for depression and suicidal ideation among PLHIV in Malawi. 
If left undiagnosed and untreated, PLHIV with depressive disorders and suicidal ideation may engage in sexual risk behaviours potentially placing HIV-uninfected sexual partners at risk for HIV acquisition. Future interventions should be developed to support HIV care clinicians in the identification and management of depression in high HIV prevalence settings.

\section{Acknowledgements}

This work was supported by the Fogarty International Center in the National Institutes of Health under the AIDS International Training Research Program (AITRP), grant (5D43 TW001039), the UNC Hopkins Morehouse Tulane Fogarty Global Health Fellows Program (R25 TW009340), and the National Institute of Mental Health training grant (5T32 AI070114).

\section{References}

1. Nakimuli-Mpungu E, Bass JK, Alexandre P, Mills EJ, Musisi S, Ram M, et al. Depression, alcohol use and adherence to antiretroviral therapy in sub-Saharan Africa: a systematic review. AIDS Behav. 2012;16(8):2101-2118. doi: 10.1007/s10461-011-0087-8

2. Sikkema KJ, Watt MH, Drabkin AS, Meade CS, Hansen NB, Pence BW. Mental health treatment to reduce HIV transmission risk behavior: a positive prevention model. AIDS Behav. 2010;14(2):252-262. doi: 10.1007/s10461-009-9650-y

3. Smit J, Myer L, Middelkoop K, Seedat S, Wood R, Bekker LG, et al. Mental health and sexual risk behaviours in a South African township: a community-based cross-sectional study. Public Health. 2006;120(6):534-542. doi: 10.1016/j.puhe.2006.01.009

4. Olley BO, Seedat S, Stein DJ. Persistence of psychiatric disorders in a cohort of HIV/AIDS patients in South Africa: a 6-month followup study. J Psychosom Res. 2006;61(4):479-484. doi: 10.1016/j. jpsychores.2006.03.010

5. Meade CS, Sikkema KJ. HIV risk behavior among adults with severe mental illness: a systematic review. Clin Psychol Rev. 2005;25(4):433457. doi: $10.1016 /$ j.cpr.2005.02.001

6. Lundberg P, Rukundo G, Ashaba S, Thorson A, Allebeck P, Östergrenet $\mathrm{P}-\mathrm{O}$, et al. Poor mental health and sexual risk behaviours in Uganda: a cross-sectional population-based study. BMC Public Health. 2011;11:125. https://doi.org/10.1186/1471-2458-11-125

7. Collins PY, Holman AR, Freeman MC, Patel V. What is the relevance of mental health to HIV/AIDS care and treatment programs in developing countries? A systematic review. AIDS. 2006;20(12):15711582. doi: 10.1097/01.aids.0000238402.70379.d4

8. Ickovics JR, Hamburger ME, Vlahov D, Schoenbaum EE, Schuman $\mathrm{P}$, Boland RJ, et al. Mortality, CD4 cell count decline, and depressive symptoms among HIV-seropositive women: longitudinal analysis from the HIV Epidemiology Research Study. JAMA. 2001;285(11):14661474. doi:10.1001/jama.285.11.1466

9. Leserman J, Pence BW, Whetten K, Mugavero MJ, Thielman NM, Swartz MS, et al. Relation of lifetime trauma and depressive symptoms to mortality in HIV. Am J Psychiatry. 2007;164(11):1707-1713. doi: 10.1176/appi.ajp.2007.06111775

10. Pence BW, Miller WC, Gaynes BN, Eron JJ, Jr. Psychiatric illness and virologic response in patients initiating highly active antiretroviral therapy. J Acquir Immune Defic Syndr. 2007;44(2):159-166. doi: 10.1097/QAI.0b013e31802c2f51

11. Nakimuli-Mpungu E, Musisi S, Katabira E, Nachega J, Bass J. Prevalence and factors associated with depressive disorders in an HIV+ rural patient population in southern Uganda. J Affect Disord. 2011;135(1-3):160-167. doi: 10.1016/j.jad.2011.07.009

12. Bhatia R, Hartman C, Kallen MA, Graham J, Giordano TP. Persons newly diagnosed with HIV infection are at high risk for depression and poor linkage to care: results from the Steps Study. AIDS Behav. 2011;15(6):1161-1170. doi: 10.1007/s10461-010-9778-9

13. Mugavero M, Ostermann J, Whetten K, Leserman J, Swartz M, Stangl D, et al. Barriers to antiretroviral adherence: the importance of depression, abuse, and other traumatic events. AIDS Patient Care STDS. 2006;20(6):418-428. doi: 10.1089/apc.2006.20.418

14. Antelman G, Kaaya S, Wei R, Mbwambo J, Msamanga GI, Fawzi WW, et al. Depressive symptoms increase risk of HIV disease progression and mortality among women in Tanzania. J Acquir Immune Defic Syndr. 2007;44(4):470-477. doi: 10.1097/QAI.0b013e31802f1318

15. Freeman M, Patel V, Collins PY, Bertolote J. Integrating mental health in global initiatives for HIV/AIDS. Br J Psychiatry. 2005;187:13. doi: 10.1192/bjp.187.1.1

16. World Health Organization. mhGAP : Mental Health Gap Action Programme : scaling up care for mental, neurological and substance use disorders. Geneva, Switzerland: World Health Organization;2008.

17. Udedi M. The prevalence of depression among patients and its detection by primary health care workers at Matawale Health Centre (Zomba). Malawi Med J. 2014;26(2):34-37.

18. National Statistical Office (NSO) [Malawi] and ICF. Malawi Demographic and Health Survey 2015-16. Zomba, Malawi, and Rockville, Maryland, USA. NSO and ICF2017.

19. Arsenault-Lapierre G, Kim C, Turecki G. Psychiatric diagnoses in 3275 suicides: a meta-analysis. BMC Psychiatry. 2004;4:37. doi: 10.1186/1471-244X-4-37

20. Cavanagh JT, Carson AJ, Sharpe M, Lawrie SM. Psychological autopsy studies of suicide: a systematic review. Psychol Med. 2003;33(3):395-405.

21. Pence BW, Gaynes BN, Atashili J, O'Donnell JK, Kats D, Whetten K, et al. Feasibility, Safety, Acceptability, and Preliminary Efficacy of Measurement-Based Care Depression Treatment for HIV Patients in Bamenda, Cameroon. AIDS Behav. 2014. 18(6):1142-51. doi: 10.1007/ s10461-014-0727-x

22. Kinyanda E, Hoskins S, Nakku J, Nawaz S, Patel V. The prevalence and characteristics of suicidality in HIV/AIDS as seen in an African population in Entebbe district, Uganda. BMC Psychiatry. 2012;12:63. doi: $10.1186 / 1471-244 \mathrm{X}-12-63$

23. American Psychiatric Association. Diagnostic and Statistical Manual of Mental Disorders, 4th ed. Washington, DC2000.

24. Pence BW, Gaynes BN, Atashili J, O’Donnell JK, Tayong G, Kats $\mathrm{D}$, et al. Validity of an interviewer-administered patient health questionnaire-9 to screen for depression in HIV-infected patients in Cameroon. J Affect Disord. 2012;143(1):208-213. doi: 10.1016/j. jad.2012.05.056

25. Cholera R, Gaynes BN, Pence BW, Bassett J, Qangule N, Macphail C, et al. Validity of the Patient Health Questionnaire-9 to screen for depression in a high-HIV burden primary healthcare clinic in Johannesburg, South Africa. J Affect Disord. 2014;167:160-166. doi: 10.1016/j.jad.2014.06.003

26. Monahan PO, Shacham E, Reece M, Kroenke K, Ong'or WO, Omollo O, et al. Validity/reliability of PHQ-9 and PHQ-2 depression scales among adults living with HIV/AIDS in western Kenya. J Gen Intern Med. 2009;24(2):189-197. doi: 10.1007/s11606-008-0846-Z

27. Pinto-Meza A, Serrano-Blanco A, Penarrubia MT, Blanco E, Haro JM. Assessing depression in primary care with the PHQ-9: can it be carried out over the telephone? J Gen Intern Med. 2005;20(8):738-742. doi: $10.1111 / \mathrm{j} .1525-1497.2005 .0144 . x$

28. Havlik RJ, Brennan M, Karpiak SE. Comorbidities and depression in older adults with HIV. Sex Health. 2011;8(4):551-559. doi: 10.1071/ SH11017

29. Shacham E, Small E, Onen N, Stamm K, Overton ET. Serostatus 
disclosure among adults with HIV in the era of HIV therapy. AIDS Patient Care STDS. 2012;26(1):29-35. doi: 10.1089/apc.2011.0183

30. Gielen AC, McDonnell KA, O'Campo PJ, Burke JG. Suicide risk and mental health indicators: Do they differ by abuse and HIV status? Women's Health Issues. 2005;15(2):89-95. doi: https://doi. org/10.1016/j.whi.2004.12.004

31. McManus H, Petoumenos K, Franic T, Kelly MD, Watson J, et al. Determinants of suicide and accidental or violent death in the Australian HIV Observational Database. PLoS ONE 9(2): e89089. doi:10.1371/ journal.pone.0089089

32. Ogundipe OA, Olagunju AT, Adeyemi JD. Suicidal ideation among attendees of a West African HIV clinic. Arch Suicide Res. 2015;19(1):103-116. doi: 10.1080/13811118.2014.915776

33. Govender RD, Schlebusch L. Suicidal ideation in seropositive patients seen at a South African HIV voluntary counselling and testing clinic. Afr J Psychiatry (Johannesbg). 2012;15(2):94-98. doi: http:// dx.doi.org/10.4314/ajpsy.v15i2.12

34. Mwale CM. The prevalence of psychological distress and associated factors among people living with aids attending antiretroviral therapy clinics in Mzuzu, Malawi: A cross sectional descriptive study [dissertation]. Malawi: College of Medicine, University of Malawi; 2006.

35. Malawi Ministry of Health. Clinical Management of HIV in Children and Adults. Department for HIV and AIDS of the Ministry of Health;2014.

36. Herce ME, Mtande T, Chimbwandira F, Mofolon I, Chingondole CK, Rosenberg NE, et al. Supporting Option B+ scale up and strengthening the prevention of mother-to-child transmission cascade in central Malawi: results from a serial cross-sectional study. BMC Infect Dis. 2015;15:328. https://doi.org/10.1186/s12879-015-1065-y
37. Palfai TP, Cheng DM, Coleman SM, Bridden C, Krupitsky E, Samet $\mathrm{JH}$. The influence of depressive symptoms on alcohol use among HIVinfected Russian drinkers. Drug Alcohol Depend. 2014;134:85-91. doi: 10.1016/j.drugalcdep.2013.09.014

38. Farley J, Miller E, Zamani A, Tepper V, Morris C, Oyegunle M, et al. Screening for hazardous alcohol use and depressive symptomatology among HIV-infected patients in Nigeria: prevalence, predictors, and association with adherence. J Int Assoc Physicians AIDS Care (Chic). 2010;9(4):218-226. doi: 10.1177/1545109710371133

39. Holahan CJ, Moos RH, Holahan CK, Cronkite RC, Randall PK. Unipolar depression, life context vulnerabilities, and drinking to cope. J Consult Clin Psychol. 2004;72(2):269-275. doi: 10.1037/0022006X.72.2.269

40. McKellar J, Ilgen M, Moos BS, Moos R. Predictors of changes in alcohol-related self-efficacy over 16 years. J Subst Abuse Treat . 2008;35(2):148-155. doi: 10.1016/j.jsat.2007.09.003

41. Ralston TE, Palfai TP. Depressive symptoms and the implicit evaluation of alcohol: the moderating role of coping motives. Drug Alcohol Depend. 2012;122(1-2):149-151. doi: 10.1016/j. drugalcdep.2011.09.011

42. Miller WR, Wilbourne PL. Mesa Grande: a methodological analysis of clinical trials of treatments for alcohol use disorders. Addiction (Abingdon, England). 2002;97(3):265-277.

43. Gonzalez JS, Batchelder AW, Psaros C, Safren SA. Depression and HIV/AIDS treatment nonadherence: a review and meta-analysis. J Acquir Immune Defic Syndr. 2011;58(2):181-187. doi: 10.1097/ QAI.0b013e31822d490a 